\title{
RNA editing: a novel mechanism for regulating lipid transport from the intestine
}

J SCOTT, S C WALlis, M S DAVIES, J K WYNNE, L M POWELL, AND D M DRISCOLL

SUMMARY Human apolipoprotein (apo)-B mRNA undergoes a novel tissue specific editing reaction which replaces a genomically templated cytidine with uridine. This substitution converts codon 2153 from glutamine (CAA) in apo-B100 mRNA to a stop codon (UAA) in apo-B48 mRNA. This novel RNA editing process is responsible for the generation of hepatic apo-B100 and intestinal apo-B48. We have established the following concerning this process: (1) by transfection of a series of deletion mutants into the rat hepatoma cell line McArdle 7777, which makes both apo-B100 and apo-B48, we have defined a minimum sequence of 26 nucleotides that is required for apo-B mRNA editing. The sequence containing the modified nucleotide forms a 26 nucleotide highly conserved stem loop with the modified nucleotide occurring in an 8-base loop. (2) Conversion in vitro of apo-B mRNA has been established, using cell free $\mathbf{S 1 0 0}$ cytoplasmic extract and synthetic RNA templates. Activity was abolished by protease treatment. (3) Transgenic mice were created which expressed a human apo-B construct spanning the stop codon. Apo-B mRNA was found in all tissues examined and this was shown to undergo editing. (4) In the rat liver, which produces apo B-100 and apo-B48, modulation of the relative proportion of these proteins by thyroxine was demonstrated to be mediated at the level of the RNA editing mechanism. It is concluded that apo-B mRNA is edited by a generally expressed protein and editing is highly regulated.

Mortality statistics for the industrialised world show that circulatory diseases are responsible for half of all deaths. ${ }^{123}$ The majority of these deaths are attributable to atherosclerosis, the cause of heart attacks, strokes, and peripheral vascular disease. Evidence from epidemiological studies, clinical trials, pathological studies in man and animals, and from genetics indicates that excessive consumption of dietary cholesterol and saturated fat is a prerequisite for the development of atherosclerosis. Cholesterol and triglyceride are transported in the circulation as lipoprotein particles. Lipoproteins consist of an oily droplet which is rendered soluble in the water of the blood by the presence on its surface of specific protein components called apolipoproteins. The largest and most important of these proteins is apolipoprotein (apo)-B.

Two forms of apo-B circulate. ${ }^{34}$ Apo-B100 is required for the assembly and secretion of endogenously synthesised cholesterol and triglyceride into the circulation as very low density lipoproteins (VLDL). This triglyceride is hydrolysed by the enzyme lipoprotein lipase in peripheral blood capillaries and fatty acid is taken up by muscle cells and adipocytes. The VLDL remnant circulates back to the liver where they undergo two distinct fates. They may be cleared from the circulation by the interaction of apo-E on the remnant surface with lipoprotein receptors on the liver cell plasma membrane. Alternatively the remnant may be acted upon by hepatic lipase present in the hepatic sinusoids and all residual triglyceride removed. The resultant cholesterol rich particle is low density lipoprotein (LDL), the main cholesterol carrying particle in blood. Apo-B100 is the sole protein of LDL, and the ligand that delivers cholesterol to cells by the LDL receptor pathway.

The complete cDNA sequence of apo-B100, ${ }^{5-9}$ and intron-exon organisation of the apo- $\mathrm{B}$ gene have been deduced. ${ }^{10-13}$ Human apo-B100 mRNA is 14121 


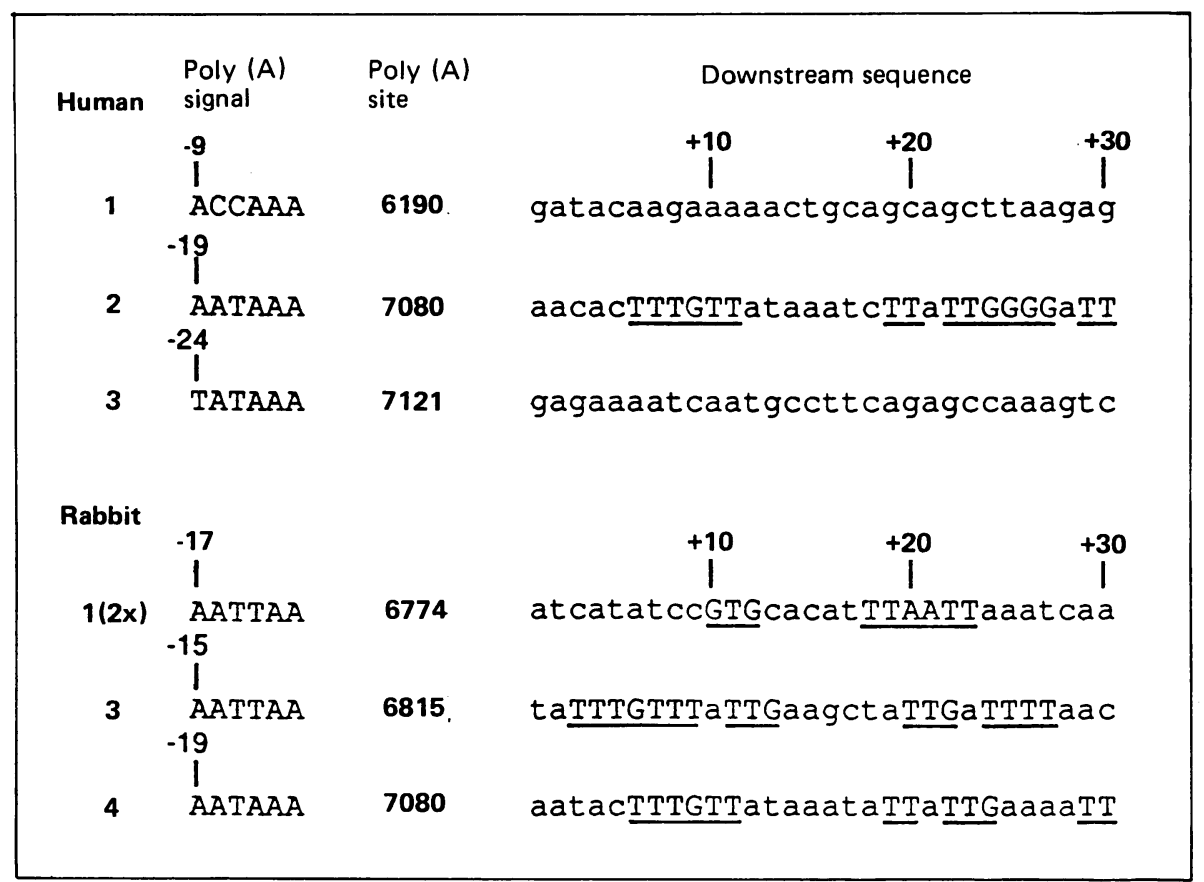

Table Position of potential polyadenylation signals relative to the sites of polyadenylation in the human and rabbit $(D) N A$ clones are shown. Apo-B48 mRNA is polyadenylated at canonical, non-canonical and grossly atypical sites. The downsteam sequences involved in polyadenylation are also shown.

nucleotides in length and encodes a 4563 amino acid precursor from which a 27 residue signal peptide is cleaved. The corresponding gene spans only 43 kilobases (kb) and is comprised of 29 exons. Over half of the coding sequence is carried by the 7572 base pair (bp) exon 26 .

A second, smaller form of apo-B, designated apoB48 on the centile system, is required for the absorption of dietary triglyceride, cholesterol and fat-soluble vitamins and for the assembly and secretion of lipoproteins called chylomicrons. ApoB48 lacks the carboxy terminal half of apo-B100 necessary for its clearance by the LDL receptor pathway. ${ }^{614}$ Chylomicrons are transported to peripheral capillaries, where the chylomicron triglyceride undergoes the same fate as VLDL triglyceride, and the chylomicron remnant circulates back to the liver. Its clearance is mediated by the interaction of apo- $\mathrm{E}$ with lipoprotein receptors.

\section{MECHANISM OF APO-B48 BIOSYNTHESIS}

Evidence from protein sequencing, peptide mapping, amino acid composition, SDS polyacrylamide gel electrophoresis, and the mapping of epitopes for monoclonal antibodies indicates that apo-B48 is colinear with the amino terminal of apo-B100. ${ }^{x+15} A$ priori, one of three well known biological mechanisms might be anticipated to explain the difference between apo-B 100 and apo-B48. First, apo-B100 and apo-B48 could be coded for by distinct genes, one coding for apo-B100 and the other for apo-B48. Second, a primary RNA transcript derived from the apo-B gene could be differentially spliced to produce either apo-B100 or apo-B48 mRNAs. Third, apoB48 could be produced by proteolytic cleavage of apo-B100. Several groups have reported northern blots showing two apo-B mRNAs in the small intestine, an abundant $14.5 \mathrm{~kb}$ mRNA, and an mRNA of approximately $7 \mathrm{~kb}$ that hybridises with $5^{\prime}$, but not with $3^{\prime}$ apo-B cDNA probes. ${ }^{i n} 16$ This last observation suggested that the first two possible explanations for the production of apo-B48 were the most likely.

To investigate the molecular basis for the production of apo-B48 we examined cDNA clones from human and rabbit small intestinal cDNA libraries and compared these with the sequences of hepatic cDNAs and genomic DNA. ${ }^{1 *}$ Detailed restriction analysis and sequencing in the region in which apoB48 was predicted to end revealed two differences between intestinal apo-B mRNA and hepatic apo-B mRNA. First, a number of human and rabbit 


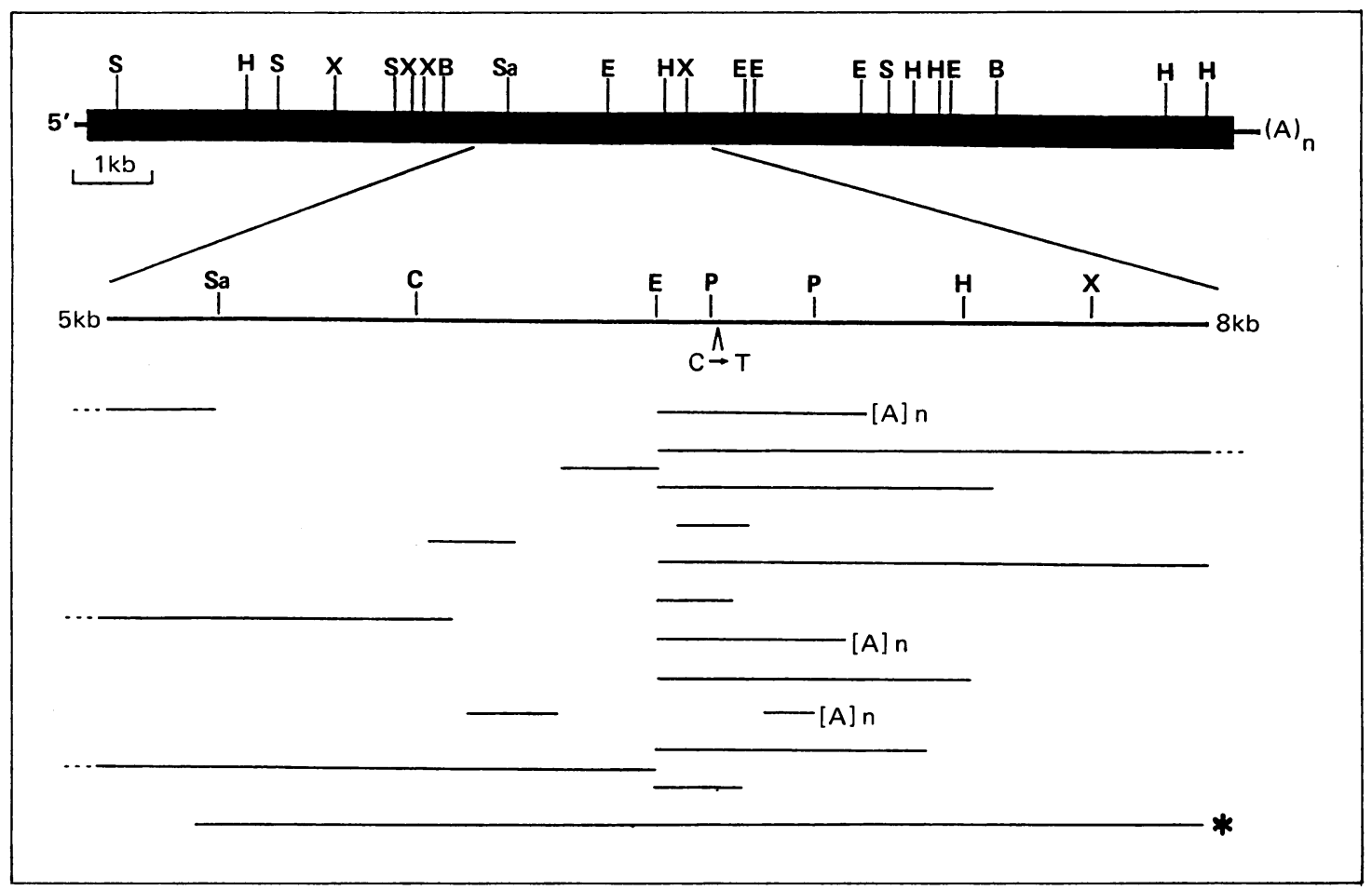

Fig. 1 Restriction map of human apo-B $c D N A s .{ }^{\prime *}$ The expanded region shows clones containing the $C$ to $T$ substitution nucleotide 6666 and three polyadenylated $c D N A s$.

intestinal cDNA clones polyadenylated at different positions (Table). Second, all of the clones examined which spanned nucleotide 6666 contained an in frame stop codon (TAA) where in the hepatic cDNA and in the apo-B gene there is a glutamine (CAA) (Fig. 1). By use of the polymerase chain reaction (PCR) and differential hybridisation with oligonucleotides designed to identify the $\mathrm{C}$ or $\mathrm{T}$ at position 6666 , we have shown that both the $14.5 \mathrm{~kb}$ and $7 \mathrm{~kb}$ mRNAs from human intestine contain mainly the apo-B48 stop codon and very little apo-B 100 glutamine codon.

To examine the possibility that there could be two apo-B genes, Southern blots of human genomic DNA were hybridised with a range of flanking sequence and internal gene probes (Figs. 2a,b). Each of the digests used gave hybridising fragments that were unique. In addition, probes that detect a hypervariable region $3^{\prime}$ to the apo-B gene reveal only two alleles in each individual (Fig. 2c). Duplication of the apo-B gene with or without this hypervariable region would produce four or three hypervariable bands respectively. We therefore concluded that it was most likely that there was only a single copy apo$B$ gene.
Apo-B48 arises in the middle of the very large $7 \cdot 5$ $\mathrm{kb}$ exon 26 of the apo-B gene (Fig. 2a arrowed). Extensive sequencing of DNA clones representing this portion of the apo-B gene, together with Southern blot analysis of human and rabbit genomic DNA derived from white blood cells, has revealed no basis for differential splicing being involved in the production of apo-B48. Amplification by the PCR of human and rabbit intestinal genomic DNA has shown that the stop codon contained in the apo-B48 mRNA is not encoded in the intestinal DNA (Figs. 3a,b,c).

From these results we have concluded that apo-B RNA undergoes a novel tissue specific editing reaction which replaces a genomically templated cytidine with uridine. This substitution converts codon 2153 from glutamine (CAA) in apo-B100 mRNA to a stop translation codon (UAA) in apo-B48 mRNA. These results have since been confirmed by other workers. ${ }^{19} 211$

\section{SEQUENCES REQUIRED FOR APO-B MRNA EDITING}

In rodents both apo-B 100 and apo-B48 are produced in the liver. Therefore to examine the sequences in apo-B mRNA required for the editing reaction a 


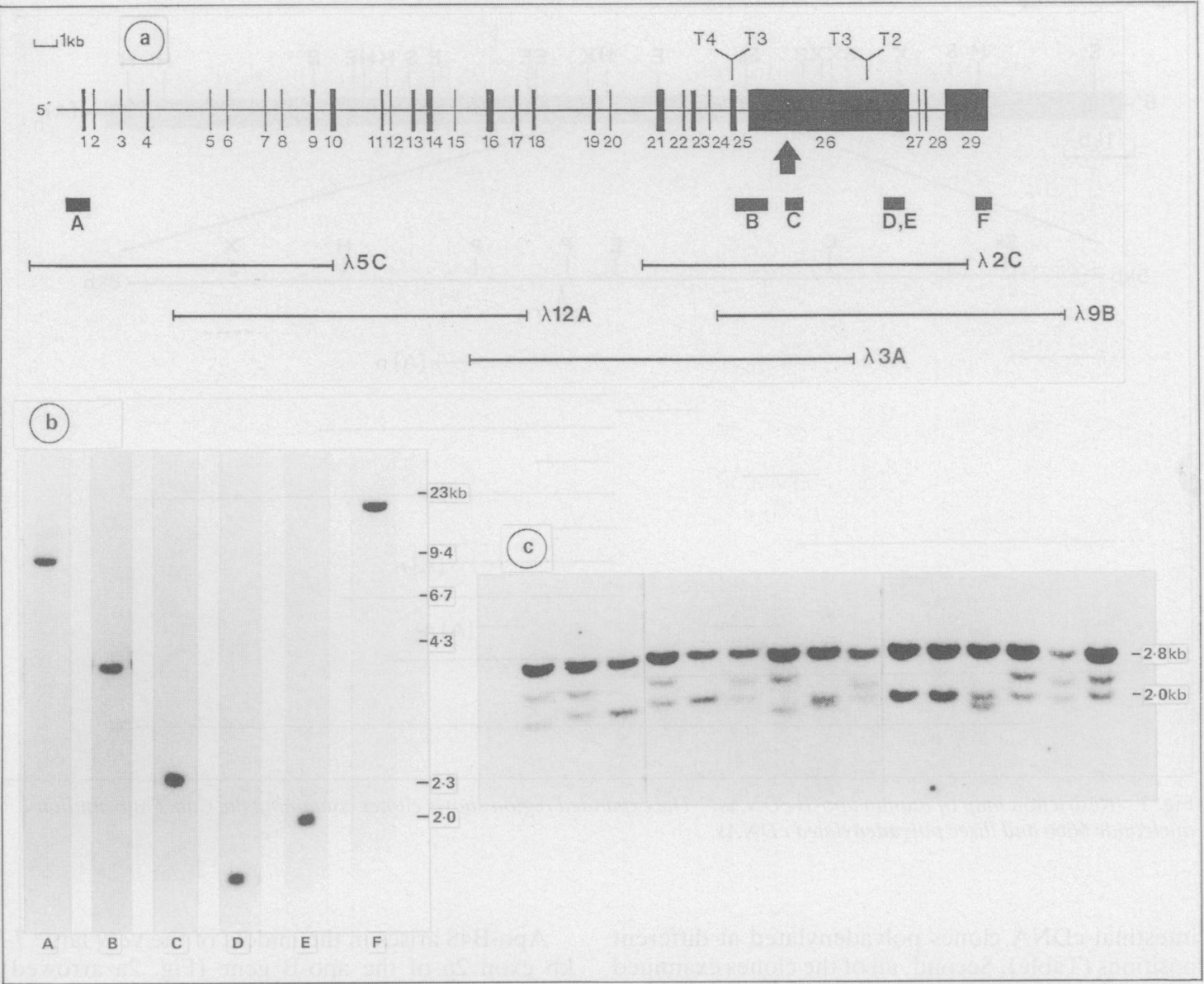

Fig. 2(a) Intron/exon organisation of the apo-B gene. Boxes $a-f$ : probes used to examine unique flanking intronic and exon 26 sequences. Lambda clones used to derive the apo-B gene sequence are shown. (b) Southern blot of unique flanking and intron fragments after digestion with EcoRI. (c) Southern blot of 3' hypervariable domain showing two allelic fragments.

series of deletion mutants expressed from an SV40 promoter (Fig. 4) encompassing the cytidine conversion site were prepared and transfected into the rat hepatoma cell line McArdle 7777 (Davies et al, manuscript submitted). This cell makes both apoB100 and apo-B48. Editing was detected on cDNA that had been amplified by PCR by a highly sensitive and specific primer extension assay (Figs 5a,b). RNAs of between 2385 and 26 bases spanning the conversion site underwent similar levels of conversion (Fig. 5b).

Comparisons of the sequence containing the modified cytidine in man, rabbits, rats and mice indicate that this sequence is highly enriched in uridine and adenosine. Secondary structure modelling of the RNA reveals that and forms a 26 base highly conserved stem loop (Fig. 6). The nucleotide under- going modification occurs in the conserved loop. The 26 base construct also forms a stem loop with the edited base in the loop.

\section{MODIFICATION IN VITRO OF APO-B RNA}

Conversion in vitro of apo-B mRNA has been established using cell free $\mathrm{S} 100$ cytoplasmic extracts and synthetic RNA templates (Fig. 7) (Driscoll et al, manuscript submitted). Extracts were prepared from McArdle 7777 cells by the method of Dignam." Active extracts were only obtained in the presence of leupeptin and antipeptin and the converting activity was found to be cryolabile. Dilution experiments indicated that approximately $2-3 \%$ of input RNA was converted. The requirements for conversion in vitro were found to be the presence of high levels of EDTA, $50 \mathrm{mM}$ being optimal. There was no require- 


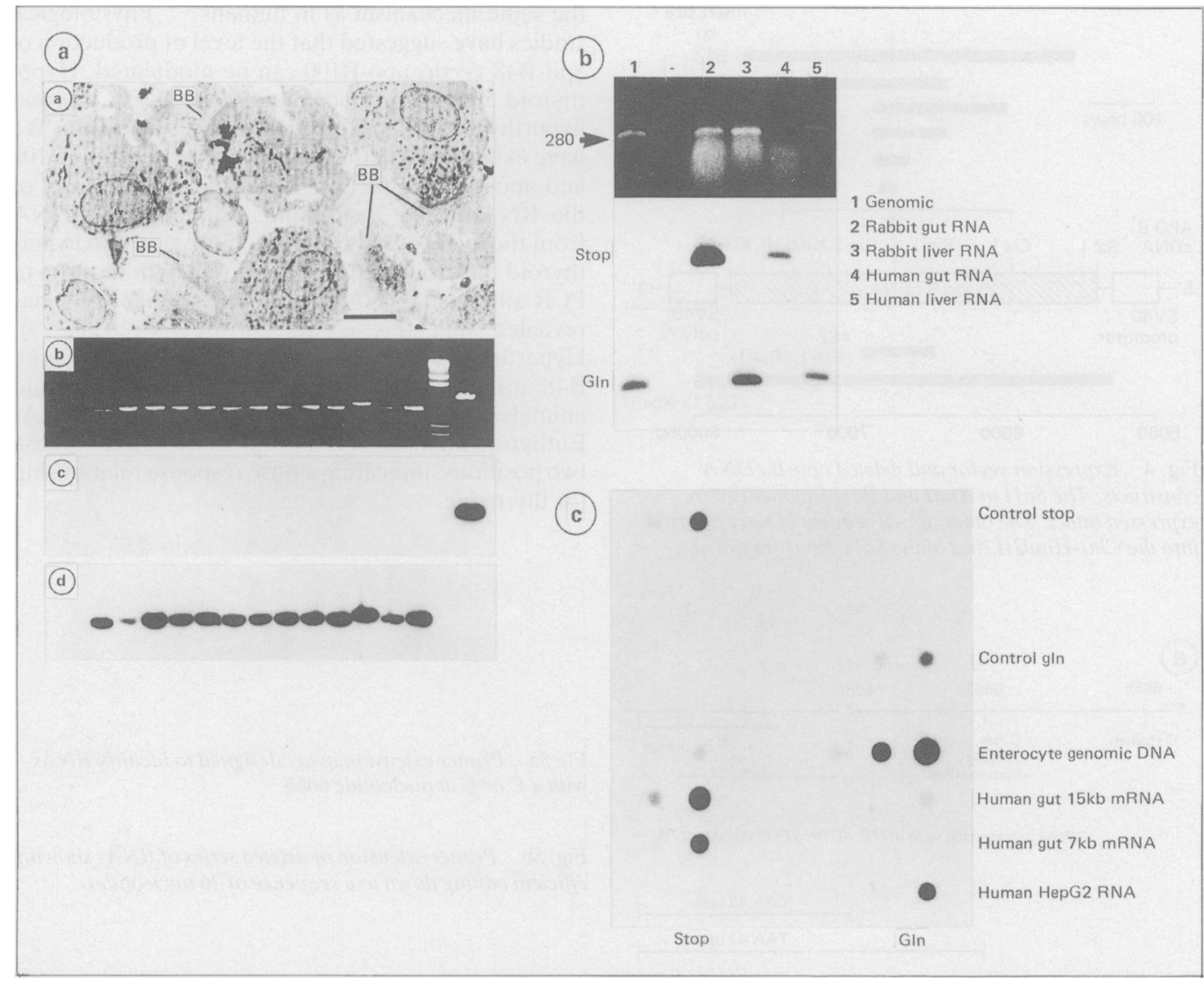

Fig. 3(a) A: electronmicrograph enterocytes used to derive intestinal DNA and RNA. B: ethidium bromide-stained agarose gel of PCR-amplified genomic DNA from the intestine. $C \& D$ : differential hybridisation with oligonucleotides designed to identify $T$ or $C$ in genomic DNA at position 6666.

(b) Ethidium bromide-stained agarose gel Southern blot of PCR products. Differential hybridisation to identify stop and glutamine codons.

(c) Dot blot of amplified genomic cDNA to demonstrate stop codon in $15 \mathrm{~kb}$ and $7 \mathrm{~b} m R N A . "$

ment for ribonucleotide triphosphates, creatine phosphate or divalent cations. Activity was abolished by treating the extracts with proteinase $\mathrm{K}$. These experiments suggest that the converting activity requires protein which is either present in the cytoplasm, or leaks into the cytoplasm during the preparation of the S100 extract. A source of energy does not appear to be required for conversion.

\section{TISSUES OTHER THAN INTESTINE AND LIVER IN} TRANSGENIC MICE EDIT APO-B MRNA

To determine whether tissues other than those normally making apo-B can edit apo-B mRNA, transgenic mice were created containing a $2 \cdot 3 \mathrm{~kb}$ human apo-B100 mRNA construct spanning the stop codon (Fig. 4). Apo-B mRNA was found in all tissues examined (Scott, et al, unpublished results). Substantial levels of conversion were shown in the intestine, spleen and lung (Fig. 8). Lower levels were shown in the liver, brain and heart. These studies suggest that all tissues, and possibly all cell types, may be capable of mediating the conversion and that it may be a general biological mechanism.

EDITING REACTION CAN BE REGULATED BY THYROXINE The rat liver produces both apo-B 100 and apo-B 48 by 


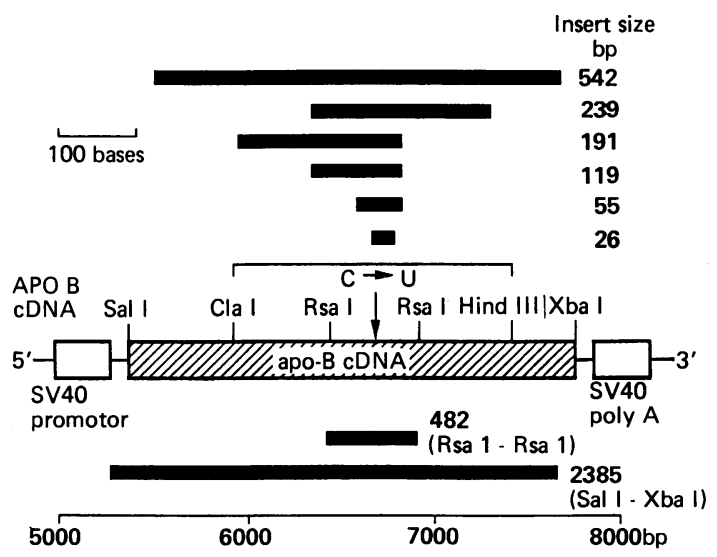

Fig. 4 Expression vector and deleted apo- $B c D N A$ constructs. The Sall to XbaI and RasI fragments were expressed intact. The other apo-B sequences were inserted into the ClaI-HindIII sites of the SaII-Xbal fragment.

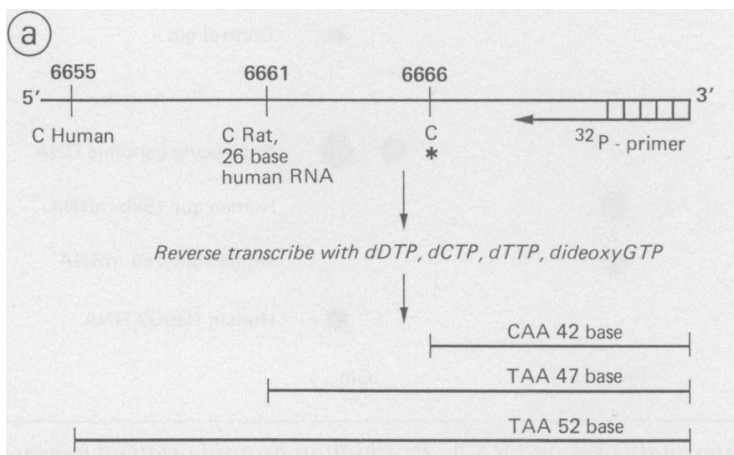

the same mechanism as in humans.": 2 Physiological studies have suggested that the level of production of apo-B48 versus apo-B 100 can be modulated. Hypothyroid animals produce mainly apo- $\mathrm{B} 100$, whereas hyperthyroid animals produce mainly apo-B 48 . We have examined whether the modulation of apo- $\mathrm{B} 100$ and apo-B48 production is mediated at the level of the RNA editing processing. Preparation of RNA from the livers of hypothyroid, euthyroid and hyperthyroid rats, followed by differential hybridisation to PCR amplified cRNA prepared from this RNA, has revealed that this is indeed the case (Fig. 9). Hyperthyroid animals contain more than $80 \%$ apoB48 mRNA in their liver, whereas hypothyroid animals contain more than $80 \%$ apo-B100 mRNA. Euthyroid animals were intermediate between these two positions, indicating a dose response relationship for thyroxine.

Fig 5a Primer extension assay designed to identify RNAs with a $C$ or $U$ at nucleotide 6666.

Fig. 5b Primer extension of deleted series of RNAs showing efficient editing down to a sequence of 26 nucleotides.

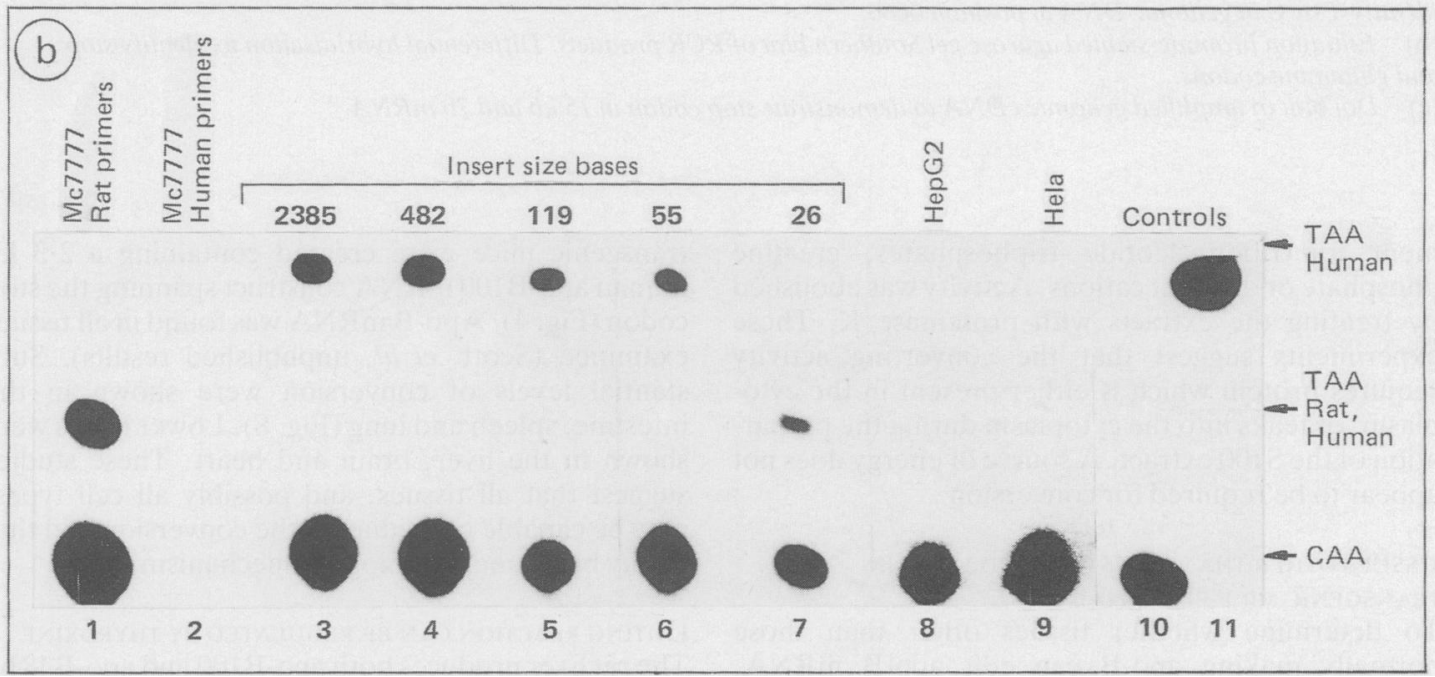




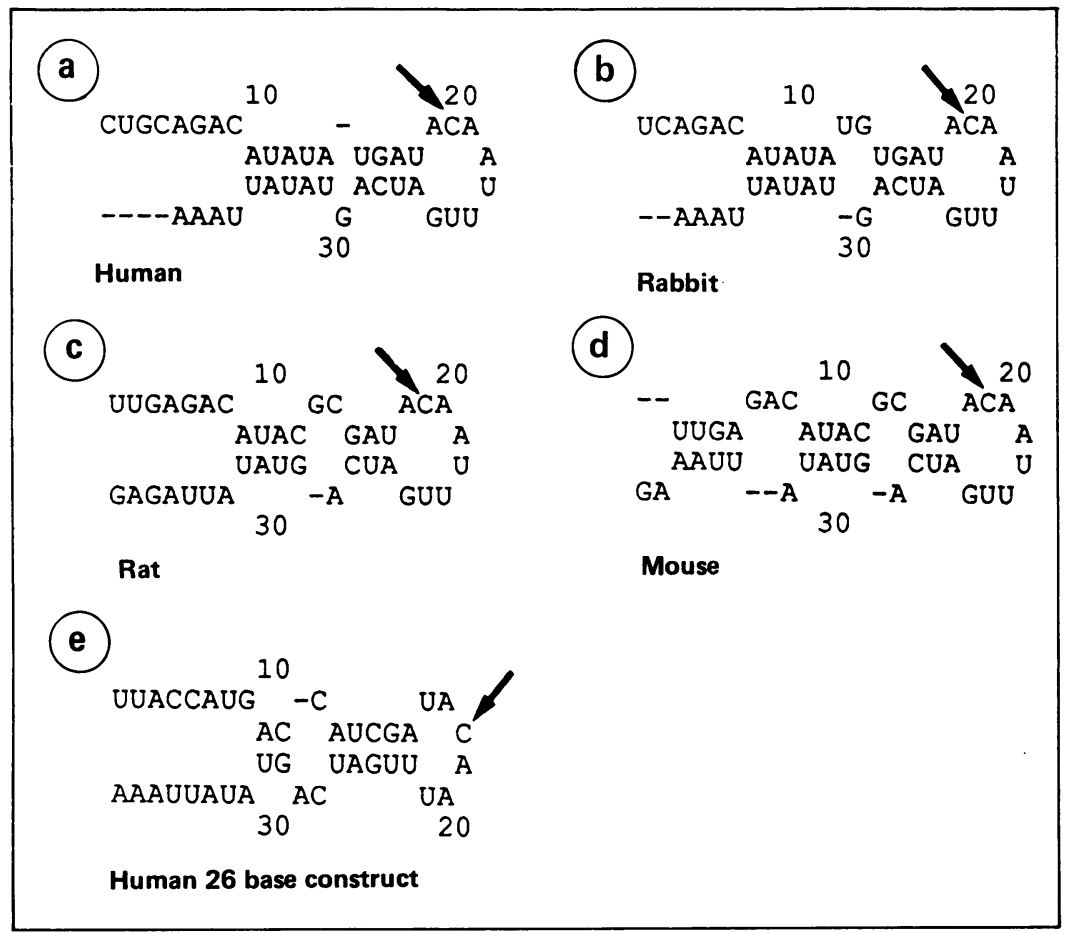

Fig. 6 Conserved UpA-rich stem loop encompassing the stop codon. The 26 base construct contains bluescript poly linked sequence. Secondary structure predictions were made using the Wisconsin programme.

\section{Discussion}

We and others have shown that apo-B100 and apoB48 are generated by a unique RNA editing

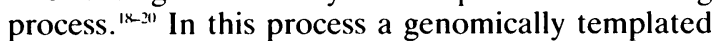
cytidine is replaced with uridine. This substitution converts codon 2153 for glutamine (CAA) in apoB100 mRNA to a stop translation codon (UAA) in apo-B48 mRNA. A 26 base highly conserved sequence is all that is required for this editing reaction. A highly conserved A-U rich stem loop is found spanning the conversion site. Editing involves a protein or proteins present in $\mathrm{S} 100$ cytoplasmic extracts. The editing process is not energy dependent. It is widely expressed in tissues that do not make apo-B. This suggests that the editing activity has a more general biological function and produces single base changes in other RNAs.

Higher mammals make apo-B48. The chick does not. Either the chick has lost the ability to make apo$\mathrm{B} 48$, or mammals have acquired this facility later in evolution. Why has this mechanism evolved, and what is the difference between mammal and chick? Consideration of the anatomical and physiological differences between the chick and higher mammals, and the structural differences between apo-B100 and apo-B48, suggests this may be related to the fate of intestinally derived lipids and lipid soluble substances.

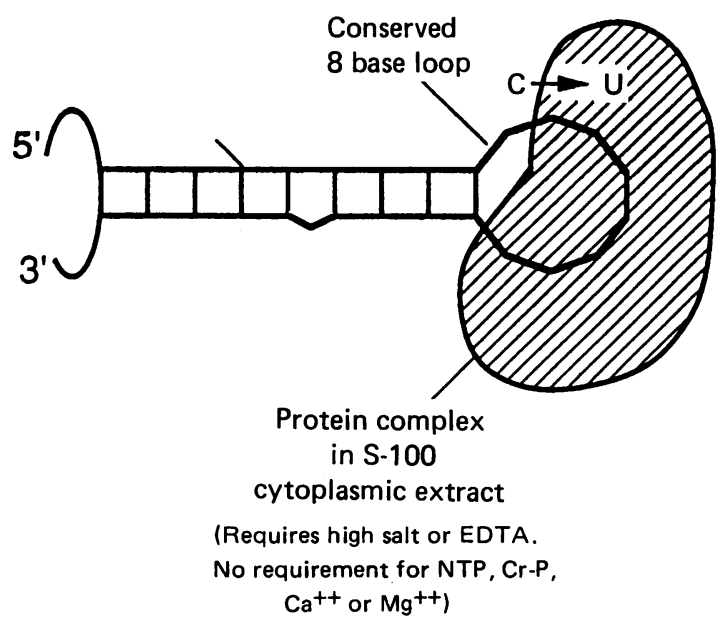

Fig. 7 Model for apo-B RNA editing. A minimum sequence encompassing a conserved stem loop shows conversion from $C$ to $U$, or a $U$-like base at position 6666 . 


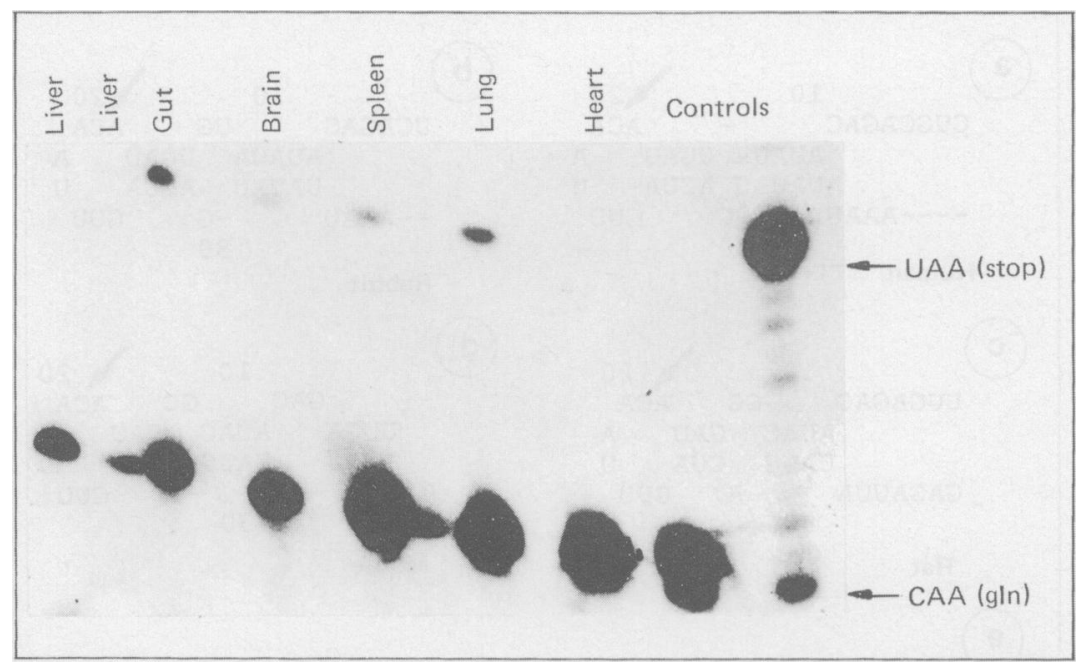

Fig. 8 Primer extension assay of RNA from tissues in transgenic mice showing positions of $U$ and $C$ and nucleotide 6666.

In mammals chylomicrons are secreted into lymphatics and passed by the thoracic duct into the blood for the transport of triglyceride to peripheral capillaries, where the triglyceride is hydrolysed and taken up to be stored or used as an energy source. The remnant of this metabolism circulates back to the liver where it is cleared from the circulation by lipoprotein receptors specific for apo-E. In the chick chylomicrons are secreted into the mesenteric vein, which enters the liver directly.

The principal domain present in apo-B100 and absent from apo-B48 is the LDL receptor binding region which mediates the clearance of LDL from the blood by the LDL receptor pathway. The half-life of LDL in the circulation is 1-2 days. Chylomicron remnants have a half-life of two to three hours, and their contents are delivered promptly to the liver. Removal of the LDL receptor binding domain from apo-B48 therefore facilitates the rapid delivery of

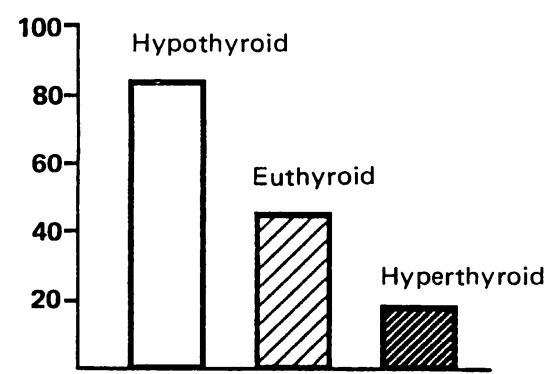

Fig. 9 Proportion of $m R N A$ encoding apo-BIOO and apo$B 48$ according to thyroid status. lipid soluble substances such as retinol, vitamin $E$, and lipid soluble coenzymes to the liver. In the chick, intestinal lipoproteins are delivered directly to the liver. Could nature have used this unique RNA editing mechanism to provide rapid access of lipid soluble vitamins, antioxidants and coenzymes to the liver?

Vitamin $\mathrm{E}$ and other fat soluble antioxidants have a critical function in maintaining the integrity of LDL apo-B against free radical attack (Jessup, Rankin, Whalley, Harding, Scott, Leake, manuscript submitted). In LDL that has been depleted of antioxidants, apo-B100 becomes fragmented and the LDL receptor binding domain destroyed. This modified LDL can no longer serve as a cholesterol delivery system and is rapidly cleared by the macrophage scavenger receptor pathway. If in mammals intestinal apo-B was solely apo-B 100 then the delivery of lipid soluble antioxidants to the liver would be markedly reduced, or would not occur. In this situation endogenously synthesised VLDL and therefore derived LDL would contain little or no protective antioxidants and would undergo rapid destruction. It is therefore speculated that nature may have evolved this most unusual mechanism because of the critical role of apo-B48 in delivering antioxidants to nascent hepatic lipoproteins.

Division of Molecular Medicine,

$M R C$ Clinical Research Centre,

Watford Road,

Harrow,

Middx HAl $3 U \mathrm{~J}$

We thank Lesley Sargeant for typing this manuscript. 


\section{References}

1 National Institutes of Health Consensus Development Pancl. Lowering blood cholesterol to prevent heart discase. Arteriosclerosis 1985; 5: 404-12.

2 DHSS. Health and personal social services statistics for England 1985. London: HMSO, 1987.

3 Scott J. The molecular and cell biology of apolipoprotein-B. Mol Biol Med 1989; 6: 65-80.

4 Kane JP. Apolipoprotein B: structural and metabolic heterogeneity. Ann Rev Physiol 1983; 45: 637-50.

5 Cladaras C, Hadzopoulou-Cladaras M, Nolte RT. Atkinson D. Zannis VI. The complete sequence and structural analysis of human apolipoprotein B100: relationship between apo-B100 and apo-B48 forms. EMBO J 1986; 5: 3495-5()7

6 Knott TJ. Wallis SC. Powell LM, et al. Complete cDNA and derived protein sequence of human apolipoprotein B100. Nucl Acids Res 1986; 14: 7501-4.

7 Law SW, Grant SM. Higuchi K, et al. Human liver apolipoprotein B100 cDNA: complete nucleic acid and derived amino acid sequence. Proc Natl Acad Sci USA 1986; 83: 8142-6.

8 Olofsson S-O, Bjursell G, Boström K, et al. Structure and biosynthesis of apolipoprotein B. Am Heart $J$ 1987; 113: 446-.52.

9 Yang C-Y, Chen S-H, Gianturco SH, et al. Sequence, structure, receptor-binding domains and internal repeats of human apolipoprotein B100. Nature 1986; 323: $738-42$.

10 Blackhart BD, Ludwig EM, Pierotti VR, Caiati L, Onasch MA. Wallis SC. Powell L, Pease R, Knott TJ, Chu M-L, Mahley RW, Scott J, McCarthy BJ, LevyWilson B. Structure of the human apolipoprotein B gene. J Biol Chem 1986; 261: 15364-7.

11 Carlsson P, Darnfors C, Olofsson S-O, Bjurscll G. Analysis of the human apolipoprotein $\mathrm{B}$ gene; complete structure of the B74 region. Gene 1986; 49: 29-51.

12 Higuchi K. Hospattankar AV, Law SW, Meglin N, Cartwright $\mathrm{J}$, Brewer HB Jr. Human apolipoprotein B (apo B) mRNA: Identification of two distinct apo B mRNAs, mRNA with the apo B-100 sequence and an apo $B$ mRNA containing a premature in-frame translational stop codon in both liver and intestine. Proc Natl
Acad Sci USA 1988; 85: 1772-6

13 Wagener R. Pfitzner R. Stoffel W. Studies on the organization of the human apolipoprotein $\mathrm{B} 1(0)$ gene. Biol Chem Hoppe-Seyler 1987; 368: 419-25.

14 Marcel YL. Innerarity TL. Spilman C. Mahley RW. Protter AA. Milne RW. Mapping of human apolipoprotein B antigenic determinants. Arteriosclerosis 1987; 7: $166-75$.

15 Hardman DA. Kane JP. Isolation and characterisation of apolipoprotein B-48. Meth Enzymol 1986; 128: 26272.

16 Deeb SS, Motulsky AG. Albers JJ. A partial cDNA clone for human apolipoprotein B. Proc Natl Acad Sci USA 1985; 82: 4983-6.

17 Mehrabian M, Schumaker VN, Fareed GC, et al. Human apolipoprotein B: identification of $\mathrm{cDNA}$ clones and characterisation of mRNA. Nucl Acids Res 1985 13: $6937-53$

18 Powell LM, Wallis SC, Pease RJ, Edwards YH. Knott TJ. Scott J. A novel form of tissue-specific RNA processing produces apolipoprotein-B48 in intestine. Cell 1987; 50: 831-40.

19 Chen S-H. Habib G. Yang C-Y, et al. Apolipoprotein B48 is the product of a messenger RNA with an organspecific in-frame translational stop codon. Science 1987 328: $363-6$.

20 Hospattankar AV. Higuchi K. Law SW, Meglin NM. Brewer HB Jr. Identification of a novel in-frame translational stop codon in human intestine apo B mRNA. Biochem Biophys Res Comm 1987; 148: 279-85.

21 Dignam TD, Lebovitz RM. Roedev RG. Accurate transcription initiation by RNA polymerase II in a soluble extract from isolated mammalian nuclei. Nucl Acid Res 1983; 11: 1475-89.

22 Davidson NO, Powell LM, Wallis SC, Scott J. (1988) Thyroid hormone modulates the introduction of a stop codon in the rat liver apolipoprotein B messenger RNA. J Biol Chem 1988; 263: 13482-5.

23 Tennyson GE, Sabatos CA, Higuchi K. Meglin N. Brewer HB Jr. (1989) Expression of apolipoprotein B mRNAs encoding higher- and lower-molecular weight isoproteins in rat liver and intestine. Proc Natl Acad Sci USA 1989; 86: 50()-4. 